\title{
Seaweed and seaweed-containing foods in the UK: focus on labeling, iodine content, toxicity and nutrition
}

\author{
M. Bouga and E. Combet \\ Human Nutrition, School of Medicine, College of Medical Veterinary and Life Sciences, University of Glasgow, \\ Glasgow, UK
}

Seaweed (or edible algae) is not a staple in the modern Western diet, despite occasional use as a sustainable and traditional ingredient in coastal areas ${ }^{(1)}$. The nutritional value of seaweed is high, being rich in carbohydrates, dietary fibre, fats and lipids, vitamins and minerals, especially iodine. Health promoting properties combined with the expansion of the health-food industry have led the transition of seaweed from traditional to functional ingredient ${ }^{(2)}$. With recent emphasis on iodine insufficiency in the British female population ${ }^{(3-5)}$, the potential of seaweed as a rich source of iodine has been further explored ${ }^{(6)}$. However, seaweed consumption can be associated with toxicity from high iodine intake, potential accumulation of arsenic, heavy metals and contaminants ${ }^{(7)}$. Here, we surveyed the current retail level of seaweed and edible algae in the UK market, either as whole foods or ingredients, with particular focus on labeling and iodine content.

A product survey took place in June 2014 to identify UK retailed products containing seaweed. The available product lists of all UK grocery retailers were searched online. Descriptive statistics were carried out (SPSS Version 21.0, IBM Corp., Armonk, NY).

Two hundred and twenty four seaweed products, belonging to ten different food categories, were identified from 29 different retailers (17 of which were selling on the high street), covering $82.2 \%$ of the UK grocery market share. Seven were considered to be large supermarkets in the UK, selling $30 \%(n=66)$ of the product range, with the other 22 specialist shops sold $70 \%(n=158)$ of the product range. The seaweed content of the products ranged from 0.1 to $100 \%$; the median price was $£ 4.0$ (interquartile range (IQR) $3 \cdot 0$ 6.8). Median packaging size was $134 \mathrm{~g}$ (IQR 50-345). Only 22 products (10\%) clearly stated quantitative information regarding iodine content and another 37 products $(17 \%)$ provided information that enabled estimation of the iodine content. For these products, the median iodine content was $110 \mu \mathrm{g} / \mathrm{g}$ (IQR 21-503) and $664 \mu \mathrm{g}$ per estimated serving (IQR 105-2520). Median iodine content of supplements was $127 \mu \mathrm{g}$ per capsule or tablet (IQR 65-368). The majority of the identified seaweed products in the UK grocery market $(64 \%, \mathrm{n}=144)$ did not have any labelling information relative to their iodine content and did not provide any information from which iodine content could be retrieved or estimated (i.e. unknown seaweed type, unknown seaweed content in the product composition, unknown seaweed iodine content). While calculations for iodine exposure per serving relied on assumptions, 21 products could potentially lead to an iodine intake above the adult upper level of tolerance of $1100 \mu \mathrm{g} / \mathrm{day}$.

The lack of information for both seaweed type contained and iodine content is a potential issue for high iodine exposure, especially for consumers who are pregnant. More detailed food labeling is required for more accurate assessment of iodine intake from seaweed products as they become more mainstream.

1. Kenicer G.; Bridgewater S.; Milliken W. Botanical Journal of Scotland 2000, 52, 119-148.

2. Brown E.M.; Allsopp P.J.; Magee P.J.; Gill C.I.R.; Nitecki S.; Strain C.R.; McSorley E.M. Nutrition Reviews 2014, 72, $205-216$.

3. Vanderpump M.P.; Lazarus J.H.; Smyth P.P.; Laurberg P.; Holder R.L.; Boelaert K.; Franklyn J.A. Lancet 2011, 377, $2007-2012$.

4. Bath S.C.; Sleeth M.L.; McKenna M.; Walter A.; Taylor A.; Rayman M.P. The British journal of nutrition 2014, 1-9.

5. Lampropoulou M.; Lean M.; Combet E.. Proceedings of the Nutrition Society 2012, 71

6. Combet E., Ma Z.F, Cousins F., Thompson B., Lean M. E. J. British Journal of Nutrition 2014, 112, 753-761.

7. Brandon E.F.; Janssen P.J.; de Wit-Bos L. Food additives \& contaminants. 2014, 31, 1993-2003. 